\title{
Distribution of Helicobacter pylori virulence markers in patients with gastroduodenal diseases in Pakistan
}

\author{
Javed Yakoob*1, Shahab Abid ${ }^{1}$, Zaigham Abbas1, Wasim Jafri1 ${ }^{1}$, \\ Zubair Ahmad ${ }^{2}$, Rashida Ahmed ${ }^{2}$ and Muhammad Islam ${ }^{1}$
}

Address: ${ }^{1}$ Department of Medicine, Aga Khan University, Karachi, Pakistan and 2 Department of Pathology, Aga Khan University, Karachi, Pakistan

Email: Javed Yakoob* - yakoobjaved@hotmail.com; Shahab Abid - shahab.abid@aku.edu; Zaigham Abbas - zaigham.abbas@aku.edu; Wasim Jafri - wasim.jafri@aku.edu; Zubair Ahmad - zubair.ahmad@aku.edu; Rashida Ahmed - rashida.ahmed@aku.edu;

Muhammad Islam - muhammad.islam@aku.edu

* Corresponding author

Published: 20 November 2009

BMC Gastroenterology 2009, 9:87 doi:10.1 I86/147|-230X-9-87

This article is available from: http://www.biomedcentral.com/I47I-230X/9/87

(C) 2009 Yakoob et al; licensee BioMed Central Ltd.

This is an Open Access article distributed under the terms of the Creative Commons Attribution License (http://creativecommons.org/licenses/by/2.0), which permits unrestricted use, distribution, and reproduction in any medium, provided the original work is properly cited.
Received: 14 May 2009

Accepted: 20 November 2009

\begin{abstract}
Background: Helicobacter pylori (H. pylori) infection is known to be associated with a spectrum of gastroduodenal diseases. We studied the association of $H$. pylori virulence markers cytotoxinassociated gene ( $\operatorname{cag} A)$ and vacuolating associated cytotoxin gene (vacA) alleles in patients with non ulcer dyspepsia (NUD), gastric ulcer (GU), gastric carcinoma (GC) and duodenal ulcer (DU).

Methods: $H$. pylori infection established by both rapid urease test and histology were studied. The cagA and vacA allelic status was determined by polymerase chain reaction (PCR). Sequencing of vacA il and i2 PCR product was carried out.
\end{abstract}

Results: Two hundred and twenty-four patients were included, I4I (63\%) were males with a mean age of $45 \pm 16$, range 16-83 years. The virulence marker cagA was associated with $\mathrm{GU}$ in 20(63\%) $(p=0.04)$, DU in $23(72 \%)(p=0.003)$ and GC in $29(73 \%)(p=0.001)$ compared to NUD in $5 \mathrm{I}(42 \%)$. VacA s l am I was associated with GU in $23(72 \%)(p=0.00 \mathrm{I})$, DU in $17(53 \%)(p<0.00 \mathrm{I})$ and GC in 23(58\%) ( $p=0.003)$ compared to NUD in 38(32\%) while vacA s $/ \mathrm{bm} /$ was also associated with GU in $9(28 \%)(p=0.00 I)$, DU in I2(37\%) $(p<0.001)$ and GC II $(28 \%)(p<0.00 I)$ compared to NUD in I3(II\%), respectively. The diagnoses of GU in $21(66 \%), D U$ in $16(50 \%), G C$ in $20(50 \%)$ and NUD in 50(42\%) were associated with moderately active chronic inflammation. CagA in $55(45 \%)(\mathrm{p}=0.037)$, vacA slam $\mathrm{in} 5 \mathrm{I}(5 \mathrm{l} \%)(\mathrm{P}<0.00 \mathrm{l}), \mathrm{s} / \mathrm{bm} /$ in $25(56 \%)(\mathrm{p}=0.002)$, slam2 $32(30 \%)(\mathrm{p}<0.00 \mathrm{I})$ and $s \mathrm{lbm} 229(69 \%)(\mathrm{p}=0.004)$ were also associated with moderately active chronic inflammation.

Conclusion: $\operatorname{CagA}$ was negative in majority of NUD patients with $H$. pylori infection. However, cagA was associated with peptic ulcer and GC. VacA allele's $\mathrm{s} / \mathrm{am} /$ and $\mathrm{s} / \mathrm{bm} /$ were associated with $H$. pylori associated diseases and inflammation.

\section{Background}

Helicobacter pylori (H. pylori) infection leads to the development of chronic gastritis and may lead to the develop- ment of duodenal and gastric ulcers, gastric adenocarcinoma and lymphoma [1-3]. The prevalence of $H$. pylori is high in developing countries. Its seropreva- 
lence in Pakistan exceeds 58\% of our general population and is common in asymptomatic population [4] A recent study revealed an early colonization/infection of infants with $H$. pylori and a prevalence of $67 \%$ at 9 months of age in a peri-urban community in Karachi, Pakistan [5]. The prevalence varies among countries with existing evidence suggesting that the diversity in disease outcome may be ascribed to variations in infecting strains $[6,7]$. Two phenotypic characteristics among $H$. pylori strains, the high molecular weight protein encoded by the cytotoxin-associated gene A ( $\mathrm{cag} A)$, and the vacuolating cytotoxin ( $\mathrm{vac}$ $A)$ have been found to be associated with distinct gastrointestinal disorders $[8,9]$. About $60-80 \%$ of $H$. pylori strains express the 120 -to- $140 \mathrm{kDa}$ cagA product that is recognized by serum antibodies [10]. Various studies have demonstrated a strong association between the presence of antibodies to cag $A$ and peptic ulcer disease and gastric carcinoma $[11,12]$. The gene encoding vacA is present in nearly all strains; however, the activity of this cytotoxin is positive in only $40-60 \%$ of patients with peptic ulcer disease and in $30 \%$ of $H$. pylori strains from patients with chronic gastritis $[12,13]$. The vacA gene present in all $H$. pylori strains comprises two variable parts, the ' $s$ ' region (encoding the signal peptide) and two alleles, 's1' and 's2' have been recognized. Within type 's1', several subtypes ( $s 1 a, s 1 b$ and $s 1 c$ ) can be distinguished [13]. For the ' $m$ ' region (middle) two alleles, ' $m 1$ ' or ' $m 2$ ', have been identified. Recently, a novel determinant of vacA called the intermediate $(i)$ region has been described [14]. It has been shown to be a better predictor of the carcinogenic potential of the $H$. pylori strains than the current signal region and midregion typing systems. The aim of this study was to investigate the distribution of tissue cagA and vacA allelic status in $H$. pylori positive gastroduodenal diseases and their associated histopathological changes in gastric mucosa.

\section{Methods \\ Patients}

Two hundred and twenty-four patients were included in the study. All patients were reported positive for $H$. pylori infection by the rapid urease test and or histology. There were $141(63 \%)$ males and $83(37 \%)$ females with a mean age of $45 \pm 16$, range 16-83 years. These patients presented with upper gastrointestinal symptoms and majority met the Rome III Diagnostic Criteria for Functional Dyspepsia i.e., at least 3 months, with onset at least 6 months previously, of 1 or more of the following: bothersome postprandial fullness, early satiation, epigastric pain or epigastric burning in the absence of structural disease to explain the symptoms [15]. The diagnosis in these patients was non ulcer dyspepsia (NUD) in 120(54\%), gastric carcinoma (GC) in $40(18 \%)$, duodenal ulcer (DU) in $32(14 \%)$ and gastric ulcer (GU) in $32(14 \%)$. Of GC
$22(15 \%)$ were in corpus, $13(33 \%)$ in antrum and $5(12 \%)$ in fundus. They were all adenocarcinomas $20(50 \%)$ were diffuse and 20(50\%) intestinal in nature. They attended the gastroenterology outpatient and endoscopy suite from June 2007 to December 2008. The study was approved by the Ethics Review Committee of Aga Khan University. All patients gave an informed consent for endoscopy and participation in the study. None of the patients had received antibiotics, acid reducing drugs such as H2-receptor antagonists, acid pump inhibitors, nonsteroidal antiinflammatory drugs or bismuth compounds in the last 4 weeks. The clinical symptoms at the time of presentation and endoscopic findings were noted. Gastric biopsy specimens were taken from an area of inflammation in the antrum and corpus. Two biopsy specimens were removed for each of the rapid urease test (Pronto Dry), histology and polymerase chain reaction (PCR). Two gastric biopsy specimens were inserted into rapid urease test (Pronto Dry). Specimens for histology were dispatched in formalin while for PCR in $0.9 \%$ normal saline. The cagA PCR for 5 ' terminal and vacA alleles for the signal " $s "$, middle " $m$ " and intermediate region " $i$ " were analyzed.

\section{Rapid Urease test}

Pronto Dry results were read in 30 minutes after sampling as directed by the manufacturer. The color change from yellow to pink was considered positive [16].

\section{Histology}

Gastric biopsy specimens for histopathology were stained with Hematoxylin and eosin (H \& E) stain for the detection of $H$. pylori and degree of gastritis. In doubtful cases, Giemsa staining was carried out to ascertain presence of H. pylori. The degree of gastritis as determined on $\mathrm{H} \& \mathrm{E}$ stain was scored in accordance with the Sydney system [17]. The presence of $H$ pylori was determined by the positive rapid urease test and histology. All biopsy specimens for histological examination were fixed in $10 \%$ formalin, embedded in paraffin wax on the oriented edge, and cut into $5 \mu \mathrm{m}$ thick sequential sections. All tissue sections were stained with hematoxylin and eosin for histological examination. The degree of acute and chronic inflammation, as well as the $H$ pylori density was scored according to the updated Sydney system. The bacterial density was graded from 0 to $3(0$, absent; 1 to 3 , from few and isolated bacteria to colonies). The infiltration of gastric mucosa by mononuclear cells and polymorphonuclear leucocytes, atrophy, and intestinal metaplasia were graded as follows: 0 , none; 1 , mild; 2, moderate; 3 , marked. Chronic inflammation was defined according to an increase in lymphocytes and plasma cells in the lamina propria graded into mild, moderate or marked increase in density. Chronic active gastritis indicated chronic inflammation with neutrophilic polymorph infiltration of the 
lamina propria, pits or surface epithelium graded as $0=$ nil, mild $=<1 / 3$ of pits and surface infiltrated; moderate $=$ $1 / 3-2 / 3$; and marked $=>2 / 3$. Antrum and corpus gastritis were scored by total sum of grade of gastritis (mild $=1$, moderate $=2$, marked $=3$ infiltration with lymphocytes and plasma cells) and activity of gastritis (mild $=1$, moderate $=2$, marked $=3$ infiltration with neutrophilic granulocytes) either in the antrum or in the corpus, a maximum of a sum of 6 points for each individual patient. Atrophy was defined as the loss of inherent glandular tissue, with or without replacement by intestinal-type epithelium. For optimal histological evaluation, all gastric biopsy specimens included surface epithelium and muscularis mucosae. Lymphoid aggregates were defined as accumulations of lymphocytes and plasma cells without a germinal centre.

\section{DNA extraction from tissues}

DNA was extracted from gastric tissue as described before [18]. Briefly, gastric tissue was homogenized to uniformity in $500 \mu \mathrm{l}$ of sterile water and centrifuged at $12,000 \times \mathrm{g}$ for 3 minutes. $500 \mathrm{ul}$ of lysis buffer $(100 \mathrm{mM} \mathrm{NaCl}, 10$ $\mathrm{mM}$ Tris- $\mathrm{HCl}$ [pH 8.0], $25 \mathrm{mM}$ EDTA, 0.5\% sodium dodecyl sulfate), and $10 \mu \mathrm{l}$ of Proteinase $\mathrm{K}(10 \mathrm{mg} / \mathrm{ml})$ was added. Incubation was carried out at $50^{\circ} \mathrm{C}$ for $20 \mathrm{~h}$; this was followed by phenol-chloroform extraction and ethanol precipitation. The resulting pellet was allowed to dissolve in $40 \mu \mathrm{l}$ of TE buffer ( $10 \mathrm{mM}$ Tris-HCl [pH 7.4] and $0.1 \mathrm{mM}$ EDTA [pH 8.0] for $20 \mathrm{~h}$ at $37^{\prime} \mathrm{C}$. Samples were stored at $-20^{\circ} \mathrm{C}$ before PCR amplification was performed. DNA content and purity was determined by measuring the absorbance at $260 \mathrm{~nm}$ and $280 \mathrm{~nm}$ using a spectrophotometer (Beckman DU-600, USA).

\section{Polymerase chain reaction}

Amplification of cag A and vac A alleles by PCR was performed in a volume of $50 \mu \mathrm{l}$ containing $10 \mathrm{mmol} / \mathrm{L}$ Tris$\mathrm{HCl}$ (pH 8.3), $50 \mathrm{mmol} \mathrm{KCl}, 1.5-2.5 \mathrm{mmol} / \mathrm{L} \mathrm{MgCl}_{2}, 200$ $\mu \mathrm{mol} / \mathrm{L}$ deoxynucleoside triphosphates, 2 units Taq DNA polymerase (Promega) and $25 \mathrm{pmol}$ of both forward and reverse primers (Table 1) used before $[14,19,20]$ (synthesized by MWG Automatic synthesizer). PCR was performed in a Perkin Elmer 9700 thermal cycler. The amplification cycles for cagA and vacA alleles are given in Table 1. Positive and negative reagent control reactions were performed with each batch of amplifications. DNA from H. pylori strains ATCC 43504 (vacAs1am1, cagA positive), ATCC 51932 (vacA $s 2 m 2$, cagA negative) and ATCC 43526 (vacA s1bm1, cagA positive) was used to define the accuracy of the cagA and $v a c A-i$ PCR and positive control DNA for $v a c A-i$ region $i 1$ and $i 2$ labeled as $97-67$ and $97-$ 72, respectively [14]. After PCR, the amplified PCR products were electrophoresed in $2 \%$ agarose gels containing $0.5 \% \times$ Tris/acetate/ethylenediaminetetraacetic acid, stained with ethidium bromide, and visualized under a short wavelength ultraviolet light source.

\section{Sequence analysis of vacA i region PCR product and BLAST Query}

The DNA fragments amplified by vacA $i$-region, type's $i 1$ and $i 2$ PCRs were purified by Qiagen quick PCR purification kit (Qiagen, USA) and sequenced using both the forward and reverse primers (Table 1) to verify that they represented truly the $H$. pylori vacuolating cytotoxin gene. Sequence analysis was performed by Macrogen (Seoul, South Korea). Sequence comparison was carried out using the Blast program and the GenBank databases.

\section{Statistical assessment}

The statistical package for social science SPSS (Release 16, standard version, copyright ${ }^{\circ}$ SPSS; 2007) was used for data analysis. The descriptive analysis was done for demographic and clinical features. Results were presented as mean \pm standard deviation for quantitative variables and number (percentage) for qualitative variables. Differences in proportion were assessed by using Pearson Chi square, Fisher exact or likelihood ratio test where appropriate. Non-parametric Kruskal-Wallis test was used to compare inflammatory score among diagnoses and virulence markers. $P$ value less than 0.05 was considered as statistically significant.

\section{Results}

The symptoms of the patients included abdominal pain $161(72 \%)$, weight loss $23(11 \%)$, vomiting $11(5 \%)$, bloating $9(4 \%)$, hematemesis $12(6 \%)$ and melena $4(2 \%)$. The endoscopic findings were gastritis in 120 patients with NUD (54\%), gastric carcinoma (GC) in 40(18\%), gastric ulcer (GU) in $32(14 \%)$ and duodenal ulcer (DU) in 32 (14\%) (Table 2). The bacterial density was grade 1 for 80 (36\%), grade 2 for $126(56 \%)$ and grade 3 for $18(8 \%)$ patients. Chronic inflammation was present in $60(27 \%)$ and chronic active inflammation in 164 (73\%).

\section{Correlation of $\mathrm{H}$. pylori genotypes with diagnosis}

The virulence marker cagA was significantly associated with peptic ulcer disease and GC (Table 2). It was positive in $31(77 \%)$ with GC, $20(62 \%)$ with GU, $23(72 \%)$ with DU compared to 51(42\%) with NUD ( $\mathrm{p}=<0.001,0.044$ and 0.003 respectively). The vacA allele $m 1$ was significantly positive in patients with GC $29(72 \%), 29(91 \%)$ in DU and $27(84 \%)$ in GU compared to only $50(42 \%)$ in NUD ( $\mathrm{p}=0.001,<0.001$ and $<0.001$, respectively). The $H$. pylori genotype cagAs1am1 was associated with GC in $22(55 \%)$ with GC, $11(34 \%)$ in DU and $11(34 \%)$ in GU compared to $22(18 \%)$ in NUD ( $\mathrm{p}<0.001,0.05$ and 0.05 , respectively). The $H$. pylori genotype cagAs $1 \mathrm{bm} 1$ was associated with GC in 10(25\%), 11(34\%) in DU and 6(19\%) 
Table I: Oligonucleotide primers used in typing of $H$. pylori cag $A$ and vac $A$ alleles

\begin{tabular}{|c|c|c|c|c|}
\hline Region Amplified & Primer designation & Primer sequence (5' to 3 ') & Size of $P C R$ product & PCR cycles \\
\hline \multicolumn{5}{|l|}{ CagA } \\
\hline \multirow[t]{2}{*}{$C-5^{\prime}$} & D008 & GGTCAAAATGCGGTCATGG & 297-bp 19 & $\begin{array}{l}\text { I cycle of } 94^{\circ} \mathrm{C} \text { for } 5 \mathrm{~min}, 35 \text { cycles of } \\
94^{\circ} \mathrm{C} \text { for } 1 \mathrm{~min}, 55^{\circ} \mathrm{C} \text { for } 1 \text { min and } \\
72^{\circ} \mathrm{C} \text { for } 90 \mathrm{sec}, 1 \text { cycle of } 72^{\circ} \mathrm{C} \text { for } \\
5 \mathrm{~min}\end{array}$ \\
\hline & R008 & $\begin{array}{l}\text { TTAGAATAATCAACAAACATCA } \\
\text { CGCCAT }\end{array}$ & & \\
\hline \multicolumn{5}{|l|}{ Vac $A$ alleles } \\
\hline \multirow[t]{2}{*}{ Sla } & SSI-F & GTCAGCATCACACCGCAAC & 190-bp 19 & $\begin{array}{l}\text { I cycle of } 95^{\circ} \mathrm{C} \text { for } 5 \mathrm{~min} ; 35 \text { cycles of } \\
95^{\circ} \mathrm{C} \text { for I min, } 52^{\circ} \mathrm{C} \text { for I min and } \\
72^{\circ} \mathrm{C} \text { for I } \mathrm{min} ; \mathrm{I} \text { cycle of } 72^{\circ} \mathrm{C} \text { for } \\
5 \mathrm{~min}\end{array}$ \\
\hline & VAI-R & CTGCTTGAATGCGCCAAAC & & \\
\hline \multirow[t]{2}{*}{ SIb } & SS3-F & AGCGCCATACCGCAAGAG & 187-bp 19 & \\
\hline & VAI-R & CTGCTTGAATGCGCCAAAC- & & \\
\hline \multirow[t]{2}{*}{ S2 } & SS2-F & GCTAACACGCCAAATGATCC & $199-b p^{19}$ & \\
\hline & VAI-R & CTGCTTGAATGCGCCAAAC & & \\
\hline \multirow[t]{2}{*}{$\mathrm{ml}$} & VA3-F & GGTCAAAATGCGGTCATGG & $290-$ bp 19 & \\
\hline & VA3-R & CCATTGGTACCTGTAGAAAC3' & & \\
\hline \multirow[t]{2}{*}{$\mathrm{m} 2$} & VA4-F & GGAGCCCCAGGAAACATTG & 352- bp 19 & \\
\hline & VA4-R & CATAACTAGCGCCTTGCAC & & \\
\hline \multirow[t]{2}{*}{ il } & Vac-FI & GTTGGGATTGGGGGAATGCCG & $426-b p^{14}$ & $\begin{array}{l}\text { I cycle of } 95^{\circ} \mathrm{C} \text { for } 90 \mathrm{sec} ; 35 \mathrm{cycles} \text { of } \\
95^{\circ} \mathrm{C} \text { for } 30 \mathrm{sec}, 53^{\circ} \mathrm{C} \text { for } 60 \mathrm{sec} \text { and } \\
72^{\circ} \mathrm{C} \text { for } 30 \mathrm{sec} ; I^{\prime} \text { cycle of } 72^{\circ} \mathrm{C} \text { for } \\
5 \mathrm{~min}\end{array}$ \\
\hline & CIR & TTAATTTAACGCTGTTTGAAG' & & \\
\hline \multirow[t]{2}{*}{ i2 } & Vac-FI & GTTGGGATTGGGGGAATGCCG & $432-b p^{14}$ & \\
\hline & $\mathrm{C} 2 \mathrm{R}$ & GATCAACGCTCTGATTTGA & & \\
\hline
\end{tabular}

in GU compared to $5(4 \%)$ in NUD ( $<<0.001,<0.001$ and 0.012 , respectively). VacA type $i 1$ was associated with GC in $33(82 \%)$, GU in $27(85 \%)$ and DU in $27(84 \%)$ while vacA type $i 2$ with NUD in 109 (90\%) (Table 2). VacAi1 was associated with $17(85 \%)$ of the intestinal type of GC and $16(80 \%)$ of the diffuse type. All the GC arising in the fundus $5(100 \%), 12(92 \%)$ in the antrum and $16(73 \%)$ in the corpus were positive for vacA i1. The prevalence of mixed infections was indicated by vacA mixed genotype patterns observed in $39(17 \%)$ of the 224 subjects $12(30 \%)$ with GC, 11(28\%) with GU, 10(26\%) with DU and $6(16 \%)$ with NUD.

\section{Correlation of histological changes with diagnosis and $\mathrm{H}$. pylori genotypes}

Marked gastritis with a high inflammatory score was seen in patients with GC compared to NUD, GU and DU (Fig 1). A high degree of inflammation was seen associated with the $H$. pylori vacA genotypes s1am1 and $s 1 b m 1$ compared to s1am2 and s1bm2 (Fig 2). Similarly, cagAs1am1 and cagAs1bam 1 were associated with a higher degree of inflammation compared to cagAs1am2 and cagAs1bm2 (Fig 3). Intestinal metaplasia was demonstrated in 5(2\%) cases, however, $3(60 \%)$ of these cases were associated with minimal inflammation with $2(2 \%)$ diagnosed as NUD and 1(3\%) with GU (Fig 1). Gastric atrophy was demonstrated in $10(5 \%)$ in the body. Lymphoid aggregates were found in 107 (48\%).

\section{Sequence analysis of vacA i region PCR product and BLAST Query}

We sequenced PCR product of VacA $i 1$ and $i 2$ with Gene Bank accession number ACN25129, ACN25130, ACN25131, ACN25132 and ACN25133. Homology of the DNA sequences to published sequences was determined by using BLAST window on the National Center for Biotechnology Information (NCBI) site at http:// www.ncbi.nlm.nih.gov/BLAST/. PCR product sequence aligned well with the sequences of vacuolating cytotoxin of different $H$. pylori strains e.g. ref [NC-000915.1] Helicobacter pylori 26695, ref [NC-000921.1] Helicobacter pylori J99, ref [NC-008086.1] Helicobacter pylori HPAG1. We randomly selected three vacAi1 and two vacAi2 PCR products for sequencing. Of the three vacAil two were from GC (GenBank ACN25129, ACN25130) and one from a DU patient (GenBank ACN25131). The sequences of $i$ region were almost identical to the vacA gene of strain 60190(GenBank U05676) except for seven mutations leading to amino acid substitution. Among these sequences, there were five conserved substitutions of N84K in cluster B (GTYNLSGL), G121S and S137L in cluster C (GANRTTTRVDFNAKNISID), D171S and K194N in cluster D (TLQASEGITSDKNAEISLYDGATLNLASNSVKLK). In these strains from GC patients G -to-S, S-to-L and D-to-S substitutions were found. In strain from NUD patient with gastritis (GenBank ACN25133) in cluster A, 
Table 2: Distribution of cagA and vacA alleles in patients

\begin{tabular}{|c|c|c|c|c|c|}
\hline \multirow[b]{2}{*}{ Virulence marker } & \multicolumn{5}{|c|}{$\begin{array}{c}\text { Diagnosis in patients } \\
n=224\end{array}$} \\
\hline & $\begin{array}{c}\text { Non ulcer dyspepsia } \\
n=120\end{array}$ & $\begin{array}{c}\text { Gastric ulcer } \\
n=32\end{array}$ & $\begin{array}{l}\text { Gastric carcinoma } \\
n=40\end{array}$ & $\begin{array}{l}\text { Duodenal ulcer } \\
\quad n=32\end{array}$ & P value* \\
\hline \multicolumn{6}{|l|}{ CagA } \\
\hline Positive & $5 I(42)$ & $20(62)$ & $31(77)$ & $23(72)$ & $<0.001$ \\
\hline Negative & $69(58)$ & $12(38)$ & $9(23)$ & $9(28)$ & \\
\hline \multicolumn{6}{|l|}{ VacAsla } \\
\hline Positive & $79(66)$ & $25(78)$ & $31(77)$ & 19(59) & 0.211 \\
\hline Negative & $41(34)$ & $7(22)$ & $9(23)$ & $13(4 \mid)$ & \\
\hline \multicolumn{6}{|l|}{ VacAsIb } \\
\hline Positive & $30(25)$ & $12(37)$ & $17(42)$ & $13(4 \mid)$ & 0.100 \\
\hline Negative & $90(75)$ & $20(63)$ & $23(58)$ & $19(59)$ & \\
\hline \multicolumn{6}{|l|}{ VacAm I } \\
\hline Positive & $50(42)$ & $27(84)$ & $29(72)$ & 29(91) & $<0.001$ \\
\hline Negative & $70(58)$ & $5(16)$ & $11(28)$ & $3(9)$ & \\
\hline \multicolumn{6}{|l|}{ VacAm2 } \\
\hline Positive & $74(62)$ & $15(47)$ & $15(37)$ & $12(37)$ & $<0.01$ \\
\hline Negative & $46(38)$ & $17(53)$ & $25(63)$ & $20(63)$ & \\
\hline \multicolumn{6}{|l|}{ VacAsIam I } \\
\hline Positive & 38 (32\%) & $23(72)$ & $23(56)$ & $17(53)$ & $<0.001$ \\
\hline Negative & $82(68 \%)$ & $9(28)$ & $17(44)$ & $15(47)$ & \\
\hline \multicolumn{6}{|l|}{ VacAsIbm I } \\
\hline Positive & $13(11)$ & $9(28)$ & II (28) & $12(38)$ & $<0.001$ \\
\hline Negative & $107(89)$ & $23(72)$ & $29(82)$ & $20(62)$ & \\
\hline \multicolumn{6}{|l|}{ CagA slam I } \\
\hline Positive & $22(18)$ & II(34) & $22(55)$ & II(34) & $<0.001$ \\
\hline Negative & $98(82)$ & $21(66)$ & $18(45)$ & $21(66)$ & \\
\hline \multicolumn{6}{|l|}{ CagA slbm I } \\
\hline Positive & $19(16)$ & II(34) & $7(18)$ & $5(16)$ & 0.01 \\
\hline Negative & 101 (84) & $21(66)$ & $33(82)$ & $27(84)$ & \\
\hline \multicolumn{6}{|l|}{ vacAi } \\
\hline il and i2 positive & $4(3)$ & 0 & $2(5)$ & 0 & $<0.001$ \\
\hline il and i2 negative & $2(2)$ & $2(6)$ & I(3) & 0 & \\
\hline il positive & $5(4)$ & $27(85)$ & $33(82)$ & $27(84)$ & \\
\hline i2 positive & $109(91)$ & $3(9)$ & $4(10)$ & $5(16)$ & \\
\hline
\end{tabular}

* Differences in proportion were assessed by using Pearson Chi square, Fisher exact or likelihood ratio test where appropriate.

K-to-Q; in cluster B R-to-I while in cluster C, A-to-T while $S$ remained $S$ and $L$ remained $L$.

\section{Accession numbers}

The sequences of two strains from GC and one from DU patient with an S-to-G substitution was deposited in GenBank (accession no. ACN25129, ACN25130, ACN25131). The strain from NUD patient with gastritis having substitution similar to GC and DU was deposited in the GenBank (accession no. ACN25132). The strain from NUD patient with gastritis for which the S remained $S$ and $L$ remained $L$ was deposited in the GenBank (accession no. ACN25133).

\section{Discussion}

The study of $H$. pylori virulence factor is important as it is associated with considerable morbidity and mortality. In
Pakistan, infection with $H$ pylori is frequent among general population and is acquired at an early age. It was found associated with dyspepsia previously in $66 \%$ of our patients [21]. The majority of our patients presenting with NUD had gastritis associated with cagA negative H. pylori. The associated vacA allelic types were vacAs1am1 and vacAs1bm1 (Table 2). On histology, gastric mucosa demonstrated both chronic and chronic active inflammation with or without lymphoid aggregate formation (Fig 2). $V a c A i$ region was not detected in $2 \%$ of the studied cases. There was a significant association of the vacA genotype $i 1$ with GC, GU and DU while vacA type i2 with NUD (Table 2 ). In another study from the northwestern part of the country, Ahmad et al in a group of 78 dyspeptics with $H$. pylori gastritis described a prevalence of positive cagA in $24.2 \%$ [22]. The common vacA genotypes were $s 1 \mathrm{bm} 2$ in (54.2\%) and s1am1 in (19.7\%) [22]. This is in contrast to 


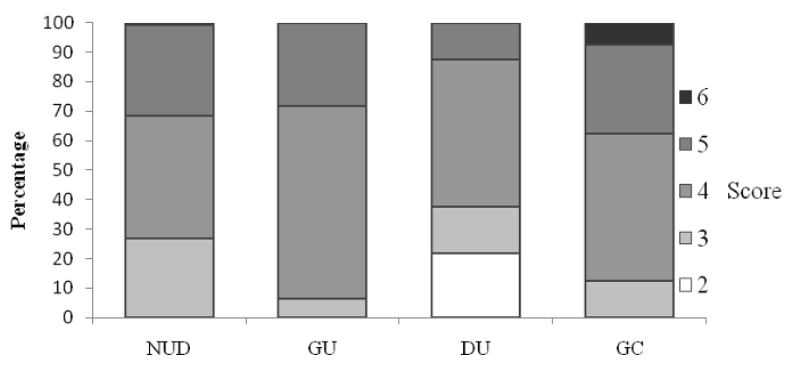

Figure I

Correlation of histological gastritis with diagnosis. *NUD = non ulcer dyspepsia; $* \mathrm{GU}=$ gastric ulcer; $* \mathrm{DU}=$ duodenal ulcer; ${ }^{*} \mathrm{GC}=$ gastric carcinoma. $*$ Gastritis score was a total sum of grade of gastritis (mild $=1$, moderate $=2$, marked $=3$ infiltration with lymphocytes and plasma cells) and activity of gastritis (mild $=1$, moderate $=2$, marked $=3$ infiltration with neutrophilic granulocytes), a maximum of a sum of 6 points for each individual patient. (Kruskal Wallis test; $p=0.005$ ).

our study where the prevalence of $\operatorname{cag} A$ was $42 \%$ and $v a c A$ genotype $1 \mathrm{am} 1$ exceeded $s 1 \mathrm{bm} 1$ in patients with NUD. In keeping with previous study, only $10(5 \%)$ were detected with genotypes vacAs $2 m 2$ and no $s 2 m 1$ was detected. Also, in our NUD patients, cagA was not significantly associated with s1am1 21(41\%) ( $\mathrm{p}=0.201)$ and majority of vacA genotypes with $s 1 \mathrm{bm} 1, \mathrm{~s} 1 \mathrm{am} 2$ and $s 1 \mathrm{bm} 2$ were cagA negative. This higher prevalence of cagA may be explained by not only an increase number of patients in our study but also that our hospital is a tertiary care referral center with a large number of patients coming across from the different parts of our country.

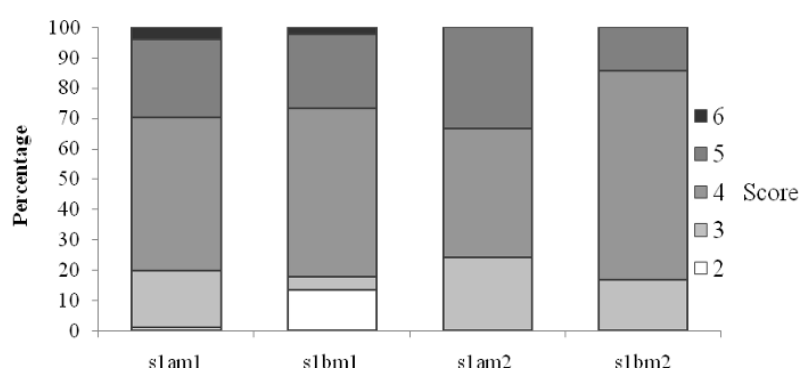

\section{Figure 2}

Correlation of histological gastritis with $\mathbf{H}$. pylori genotypes. *Gastritis score was a total sum of grade of gastritis $($ mild $=1$, moderate $=2$, marked $=3$ infiltration with lymphocytes and plasma cells) and activity of gastritis (mild $=$ $\mathrm{I}$, moderate $=2$, marked $=3$ infiltration with neutrophilic granulocytes), a maximum of a sum of 6 points for each individual patient. (Kruskal Wallis test; $p=0.72 \mathrm{I}$ ).

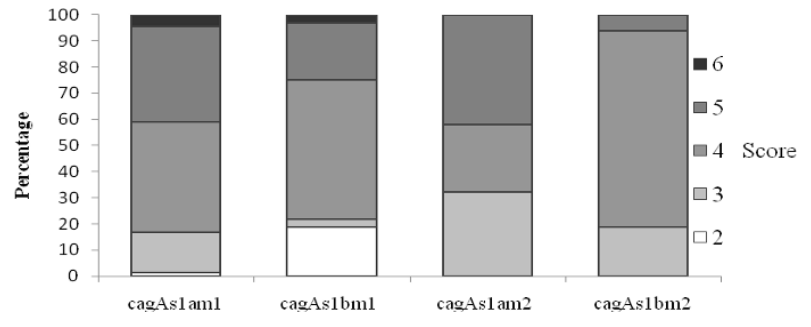

\section{Figure 3}

Correlation of histological gastritis with $\mathbf{H}$. pylori

genotypes. *Gastritis score was a total sum of grade of gastritis ( mild $=1$, moderate $=2$, marked $=3$ infiltration with lymphocytes and plasma cells) and activity of gastritis (mild = $\mathrm{I}$, moderate $=2$, marked $=3$ infiltration with neutrophilic granulocytes), a maximum of a sum of 6 points for each individual patient. (Kruskal Wallis test; $p=0.163$ ).

This H. pylori virulence pattern in patients with peptic ulcer and GC were similar to the one described in Iran, India and Bangladesh [23-25]. A cagA prevalence of 76\% was found in Iranian isolates [23]. PCR tests indicated that 80 to $90 \%$ of Calcutta strains carried the cag pathogenicity island (PAI) and potentially toxigenic vacAs1 alleles of the $v a c A$, independent of disease status [24]. In Bangladesh, cagA was present in $75 \%$ of the strains from patients with peptic ulcer (PU) compared to $55 \%$ in patients with NUD, and $80 \%$ from PU carried potentially toxigenic vacAs1 alleles compared to $60 \%$ in isolates from patients with NUD [25]. However, no significant difference in any other virulence marker was observed in isolates from both groups. Phylogenetic analysis of the vacA $m$ region and the 5 ' end of the $\operatorname{cag} A$ gene indicated that Bangladeshi isolates were more closely related to $H$. pylori isolates from India and were different from isolates from East Asia [25]. A relationship was described by Rhead et al between $i 1$ and GC while Hussein et al finding no such relationship found $i 1$ associated with GU in Iraq isolates [14,23]. Recently, Basso et al found an association of $i 1$ not only with GC but also with DU in Italian isolates [26]. Our results concur with $i 1$ association with GC, GU and DU.

\section{Conclusion}

In our patients, the overall prevalence of $c a g A$ positive $H$. pylori infection is low, $56 \%$ compared to over $70 \%$ seen in neighboring countries, Iran, India and Bangladesh. It may possibly be explained by the lack of genetic predisposition and/or low frequency of particularly virulent cagA positive strain in this area. Karachi is a metropolitan city with people from different racial descent migrating to this part of the country may have resulted in the dilution of particularly virulent strains. 


\section{Competing interests}

The authors declare that they have no competing interests.

\section{Authors' contributions}

JY conceived and designed the study, JY, SA, ZA, WJ coordinated the study, JY did the work, JY, ZA, RA, analyzed the data, JY and MI performed the statistical analysis. JY wrote the manuscript. All authors read and approved the final manuscript

\section{Acknowledgements}

This work was carried out by the Aga Khan University Research Grant SM $100327 * 11$ 43I and 0410I4 MED. We are grateful to Professor John Atherton for providing controlled DNA to perform VacA intermediate region analysis and for his helpful comments. We are also grateful to $\mathrm{Dr}$ Mushtaq Hussain, Dr Anila Yasmeen and Dr Zulfiqar Naqvi, Department of Biomedical Sciences, The Aga Khan University for their assistance in the data analysis. We are also thankful to staff members at the Juma Research Building, Aga Khan University for their assistance during this work.

\section{References}

I. Blaser MJ: Ecology of Helicobacter pylori in the human stomach. I Clin Invest 1997, 100:759-762.

2. Cover TL, Blaser MJ: Helicobacter pylori factors associated with disease. Gastroenterology 1999, I I 7:257-26I.

3. Parsonnet J, Friedman GDS, Vandersteen DP, Chang Y, Vogelman JH, Orentreich N, Sibley RK: Helicobacter pylori infection and risk of gastric carcinoma. N Engl] Med I99|, 325:II27-II3I.

4. Abid S, Hussain T, Rabbani F, Ahmed A: Seroprevalence and risk factors for $\boldsymbol{H}$. pylori. A Population Based Study. Helicobacter 2003, 8:A6.

5. Nizami SQ, Bhutta ZA, Weaver L, Preston T: Helicobacter pylori colonization in infants in a peri-urban community in Karachi, Pakistan. I Pediatr Gastroenterol Nutr 2005, 4:191-194.

6. Go MF, Graham DY: How does $\boldsymbol{H}$. pylori cause duodenal ulcer disease: The bug, the host or both? I Gastroenterol Hepatol 1994 9:S8-12.

7. Malaty HM, Engstrand L, Pedersen NL, Graham DY: Helicobacter pylori infection: genetic and environmental influences. A study of twins. Ann Intern Med 1994, I 20:982-986.

8. Censini S, Lange C, Xiang Z, Crabtree JE, Ghiara P, Borodovsky M, Crabtree JE, Ghiara P, Borodovsky M, Rappuoli R, Covacci A: cag Apathogenecity island of $\boldsymbol{H}$. pylori encodes type I- specific and disease-associated virulence factors. Proc Natl Acad Sci USA 1996, 93:14648-|4653.

9. Atherton JC, Cao P, Peek RM, Tummuru MKR, Blaser MJ: Mosaicism in vacuolating cytotoxin alleles of $H$. pylori: association of specific vacA types with cytotoxin production and peptic ulceration. J Biol Chem 1995, 270: I777I-I7777.

10. Cover TL, Donley CP, Blaser MJ: Characterization of human serological response to proteins in $\mathrm{H}$. pylori broth culture supernatants with vacuolizing cytotoxin activity. Infect Immun 1990, 58:603-610.

II. Weel JF, Hulst RW van der, Y Gerrits, Tytgat GN, Ende A van der, Dankert J: Inter relationship between cytotoxin- associated gene $\mathbf{A}$, vacuolating cytotoxin and Helicobacter pylori-related diseases. J Infect Dis 1996, I 73: I I7I-II75.

12. Tee W, Lambert JR, Dwyer B: Cytotoxin production by H. pylori from patients with upper gastrointestinal tract disease. J Clin Microbiol 1995, 33:1203-1205.

13. van Doorn LJ, Figueiredo C, Sanna R, Pena S, Midolo P, Ng EK, Atherton JC, Blaser MJ, Quint WG: Expanding allelic diversity of Helicobacter pylori vacA. J Clin Microbiol 1998, 36:2597-25603.

14. Rhead JL, Letley DP, Mohammadi M, Hussein N, Mohagheghi MA Eshagh Hosseini M, Atherton JC: A new Helicobacter pylori vacuolating cytotoxin determinant, the intermediate region, is associated with gastric cancer. Gastroenterology 2007 , 133:926-936.

15. Drossman DA: Rome III: The new criteria. Chinese J of Digest Dis 2006, 7:181-185.
16. Morio O, Rioux-Leclercq N, Pagenault M, Corbinais S, Ramee MP, Gosselin M, Bretagne JF: Prospective evaluation of a new rapid urease test (Pronto Dry) for the diagnosis of Helicobacter pylori infection. Gastroenterol Clin Biol 2004, 28((6-7 Pt I)):6-7.

17. Price AB: The Sydney System: histological division. J Gastroenterol Hepatol 1991, 6:209-222.

18. Van Zwet AA, Thijs C, Kooistra-Smid, Schirm J, Snijder JAM: Sensitivity of culture compared with that of polymerase chain reaction for detection of Helicobacter pylori from antral biopsy samples. J Clin Microbiol 1993, 31:1918-1920.

19. Covacci A, Rappuoli R: PCR amplification of gene sequences from Helicobacter pylori strains. In Helicobacter pylori: Techniques for clinical diagnosis and basic research Philadelphia; W. B. Saunders; 1996:94-109.

20. Occhialini A, Marais A, Urdaci M, Sierra R, Muñoz N, Covacci A Mégraud F: Composition and gene expression of the cag pathogenicity island in $\mathbf{H}$. pylori strains isolated from gastric carcinoma and gastritis patients in Costa Rica. Infect Immun 200 I, 69:1902-1908.

21. Mumtaz K, Abid S, Yakoob J, Abbas Z, Hamid S, Islam M, Shah HA Jafri W: An office-based serological test for detection of current Helicobacter pylori infection: is it useful? Eur J Gastroenterol Hepatol 2006, I 8:85-88.

22. Ahmad T, Sohail K, Rizwan M, Mukhtar M, Bilal R, Khanum A: Prevalence of Helicobacter pylori pathogenicity-associated cagA and vacA genotypes among Pakistani dyspeptic patients. FEMS Immunol Med Microbiol 2009, 55:34-38.

23. Hussein NR, Mohammadi M, Talebkhan Y, Doraghi M, Letley DP, Muhammad MK, Argent RH, Atherton JC: Differences in virulence markers between Helicobacter pylori strains from Iraq and those from Iran: potential importance of regional differences in H. pylori-associated disease. J Clin Microbiol 2008, 46: I774- I779.

24. Mukhopadhyay AK, Kersulyte D, Jeong JY, Datta S, Ito Y, Chowdhury A, Chowdhury S, Santra A, Bhattacharya SK, Azuma T, Nair GB, Berg DE: Distinctiveness of genotypes of Helicobacter pylori in Calcutta, India. J Bacteriol 2000, I 82:3219-3227.

25. Rahman M, Mukhopadhyay AK, Nahar S, Datta S, Ahmad MM, Sarker S, Masud IM, Engstrand L, Albert MJ, Nair GB, Berg DE: DNA-level characterization of Helicobacter pylori strains from patients with overt disease and with benign infections in Bangladesh. | Clin Microbiol 2003, 4I:2008-20 I 4.

26. Basso D, Zambon CF, Letley DP, Stranges A, Marchet A, Rhead JL, Schiavon S, Guariso G, Ceroti M, Nitti D, Rugge M, Plebani M, Atherton JC: Clinical relevance of Helicobacter pylori cagA and vacA gene polymorphisms. Gastroenterology 2008, I35:91-99.

\section{Pre-publication history}

The pre-publication history for this paper can be accessed here:

\section{http://www.biomedcentral.com/1471-230X/9/87/pre} pub

Publish with Biomed Central and every scientist can read your work free of charge

"BioMed Central will be the most significant development for disseminating the results of biomedical research in our lifetime. "

Sir Paul Nurse, Cancer Research UK

Your research papers will be:

- available free of charge to the entire biomedical community

- peer reviewed and published immediately upon acceptance

- cited in PubMed and archived on PubMed Central

- yours - you keep the copyright
BioMedcentral 